\title{
Gêneros e espécies novos de Mesembrinellinae (Diptera, Calliphoridae) da Costa Rica e Venezuela ${ }^{1}$
}

\author{
Sionei R. Bonatto ${ }^{2} \&$ Luciane Marinoni ${ }^{2}$ \\ ${ }^{1}$ Contribuição número 1592 do Departamento de Zoologia, Universidade Federal do Paraná. \\ 2 Departamento de Zoologia, Universidade Federal do Paraná. Caixa Postal 19020, 81531-980 Curitiba, Paraná, Brasil. \\ Bolsista do CNPq. E-mail: sbonatto@ufpr.br; Imarinoni@ufpr.br
}

\begin{abstract}
New genera and species of Mesembrinellinae (Diptera, Calliphoridae) from Costa Rica and Venezuela. The following new taxa are described: Henriquella gen. nov. (type-species Mesembrinella spicata from Costa Rica, La Suiza), Giovanella gen. nov. with Giovanella bolivar sp. nov. (type-species) from Venezuela, Bolivar, and Huascaromusca lara sp. nov. Venezuela, Lara. Mesembrinella spicata Aldrich, 1925 formerly considered as synonym of Calliphora xanthorrhina Bigot, 1887, is reinstated and transferred into Henriquella gen. nov., becoming Henriquella spicata (Aldrich, 1925) sp. rev., comb. nov. Illustrations of the holotypes, including the respective terminalia, are also given.
\end{abstract}

KEY WORDS. Blowflies, Neotropical, systematic, taxonomy.

RESUMO. São descritos os seguintes novos táxons: Henriquella gen. nov. (espécie-tipo Mesembrinella spicata da Costa Rica, La Suiza), Giovanella gen. nov. com Giovanella bolivar sp. nov. (espécie-tipo) da Venezuela, Bolivar e Huascaromusca Iara sp. nov. da Venezuela, Lara. Mesembrinella spicata Aldrich, 1925 anteriormente considerada como sinonímo de Calliphora xanthorrhina Bigot, 1887, é restabelecida e transferida para Henriquella gen. nov., tornando-se Henriquella spicata (Aldrich, 1925) sp. rev., comb. nov. Ilustrações dos holótipos, incluindo as respectivas terminálias, também são fornecidas.

PALAVRAS CHAVE. Califorídeos, Neotropical, sistemática, taxonomia.

Mesembrinellinae é um pequeno grupo de dípteros exclusivamente Neotropical, cujas espécies têm distribuição desde o sul do México (Yucatán) até o norte da Argentina (Misiones) ainda não havendo registro para o Chile e para as Antilhas, exceto Trinidad (Guimarães 1977, Peris \& Mariluis 1984). Tradicionalmente, tem sido reconhecida como uma das cinco subfamílias de Calliphoridae, com base nos estados de caracteres do plano básico dos califorídeos, compartilhados entre estes dois grupos (HenNig 1973, McAlpine 1989).

Através de um aprofundado estudo de revisão das espécies desta subfamília, tivemos a oportunidade de examinar exemplares provenientes de diversas instituições nacionais e estrangeiras, incluindo praticamente todo o material-tipo concernente.

No presente trabalho são descritos dois novos gêneros e duas novas espécies, a partir de material coletado na Costa Rica e Venezuela, descobertos entre os exemplares examinados na coleção do National Museum of Natural History, Washington, D.C., EUA (USNM). Ainda, uma espécie, tida como sinônimo júnior, é revalidada.

Para o material-tipo examinado foram transcritas as informações das etiquetas seguindo a simbologia adotada por
Carvalho \& Couri (1992): (" ") para indicar o início e fim da uma etiqueta; (/) para indicar o início e fim de uma linha, dentro de uma mesma etiqueta; ([) para informações pessoais ou esclarecimentos complementares, não contidos na etiqueta.

Foi seguida a terminologia proposta por McAlpine (1981), a qual procura padronizar a nomenclatura estrutural, levando em conta sempre que possível considerações sobre homologias. Entretanto, no caso das estruturas relacionadas com o pronoto e designação de quetotaxia, foram adotadas as de O'HARA (1982) e Rognes (1991), as quais demonstram ser mais consistentes e coerentes. O termo "pruinosidade", utilizado na descrição de certos caracteres, tem o significado conforme MARINONI \& KNUTSON (1992: 26).

Abreviaturas utilizadas no texto. Instituições depositárias de material: (USNM) National Museum of Natural History, Washington, D.C., EUA, (DZUP) Coleção de Entomologia Padre Jesus Santiago Moure, Departamento de Zoologia, Universidade Federal do Paraná, Curitiba, Paraná, Brasil. Cerdas: (Acr) acrosticais, (Anp) anepisternais, (Cat) catepisternais, (Dc) dorsocentrais, (Eap) escutelares apicais, (Esb) escutelares basais, (Esd) escutelares discais, (Epb) escutelares pré-basais, (Esa) 
escutelares sub-apicais, (IA) intra-alares, (Pep) proepimerais, (Prs) pré-suturais, (PA) pós-alares, (Psu) pós-umerais, (SA) supra-alares, (Ume) umerais (pospronotais de McAlpine (1981)), (Vte) verticais externas, (Vti) verticais internas; escleritos: $\left(\mathrm{St}_{6-8}\right)$ sexto a oitavo esternitos, $\left(\mathrm{T}_{1-8}\right)$ primeiro a oitavo tergitos abdominais; veias alares: $(C)$ costal, $(M)$ mediana, $\left(R_{1}\right)$ radial $1,\left(R_{2+3}\right)$ radial $2+3$, $\left(\mathrm{R}_{4+5}\right)$ radial $4+5$, (Sc) subcostal, (Vtr) veia tronco (remigium); células alares: $(\mathrm{m})$ mediana, $\left(\mathrm{r}_{1}\right)$ radial $1,\left(\mathrm{r}_{2+3}\right)$ radial $2+3$.

\section{Giovanella Bonatto, gen. nov.}

Espécie-tipo: Giovanella bolivar Bonatto, sp. nov.

Descrição. Cerdas acrosticais ausentes, intra-alares 0:1, asas com mácula alar desde a base até o ápice da $\mathrm{R}_{2+3}$, com intensa ofuscação ao longo de todas as veias; $\mathrm{T}_{5}$ sem discais; espiráculos anteriores muito desenvolvidos com abertura reduzida (Fig. 8) quando comparada com o padrão encontrado na subfamília (Fig. 7).

Monofilia. A monofilia do gênero pode ser suportada pelos seguintes estados de caracteres: abertura reduzida e em fenda dos espiráculos anteriores (compare figuras 7 e 8) e redução do número de cerdas intralares, com padrão 0:1. Embora o padrão de abertura dos espiráculos anteriores possa ser analisado como plesiomórfico, por ocorrer em estado semelhante em grupos externos à Mesembrinellinae, este estado é único entre as espécies da subfamília, sendo interpretado como uma aquisição secundária.

Etimologia. Nome em homenagem à nossa filha Giovana Marinoni Bonatto, nascida durante o desenvolvimento deste estudo.

Considerações. Gênero muito próximo à Huascaromusca Townsend, 1918, com o qual compartilha diversos caracteres e por outro lado, também com Thompsoniella Guimarães, 1977. Quando for estabelecido o relacionamento entre as espécies de Huascaromusca, não se descarta a possibilidade de que alguma de suas espécies, venha a ser alocada em Giovanella gen. nov.

\section{Giovanella bolivar Bonatto, sp. nov. Figs $1-2,8-15$}

Diagnose. Ocelares e pós-ocelares vestigiais; espiráculo anterior com abertura em fenda, como na figura 8; acrosticais ausentes, intra-alares 0:1, fêmeas com duas pós-alares; asa com mácula alar desde a base até o ápice da $\mathrm{R}_{2+3}$, com intensa ofuscação ao longo de todas as veias; todos os fêmures amarelos, com quarto apical enegrecido; $\mathrm{T}_{5}$ sem discais; macho com $\mathrm{T}_{6}$ assimétrico, parcialmente fundido ao $\mathrm{T}_{7+8}$; extremidade do parafalo muito recurvada e sem dentículos.

Condição autapomórfica. O espiráculo anterior com abertura em fenda (Fig. 8), é um estado único para a espécie dentro da família, além da redução no número de cerdas intra-alares para $0: 1$.

Descrição. Holótipo macho. Cabeça: holóptica; fronte totalmente obliterada, inexistente na altura do vértice, com região basal castanho-alaranjada, alargando-se abruptamente ao aproximar-se da lúnula, na porção mais estreita com a metade do diâmetro do ocelo anterior; parafrontálias e parafaciálias negras com pruinosidade prateada e sétulas; genas amarelo-alaranjadas com fraca pruinosidade branca e reduzidas sétulas negras; pósgenas com pêlos alaranjados; face e membrana clipeal claras; triângulo ocelar negro e reduzido; pedicelos, escapos e flagelômeros castanhos; palpos alaranjado; occipício com pruinosidade branca nos $2 / 3$ basais e com pêlos flavos presentes somente na porção pruinosa. Quetotaxia: ocelares e pós-ocelares vestigiais; verticais externas ausentes; verticais internas cruzadas; um par de paraverticais fracas cruzadas; pós-oculares reduzidas no ápice distribuídas homogeneamente até a gena; interfrontais e orbitais proclinadas ausentes; carena facial enegrecida, pouco proeminente (proeminente somente na região de inserção das vibrissas, o restante no mesmo nível da face), base com três pequenas sétulas acima da vibrissa; vibrissas cruzadas; subvibrissas com 2/3 do comprimento das vibrissas.

Tórax. Mesonoto castanho-avermelhado, com regiões enegrecidas, com densa e fina pruinosidade branca recobrindo todo o tórax; pleura como o mesonoto porém com áreas do mero e catepisterno alaranjadas mais claras; úmeros alaranjados; espiráculos anteriores amarelo-alaranjados com abertura em fenda a partir da metade apical; espiráculos posteriores com a mesma cor do anterior com poucas sétulas curtas e negras na porção basal posterior; coxas amarelas, a mediana castanho-clara, todos os fêmures alaranjados com o 1/4 apical castanho; tíbias castanhoescuras; fêmures medianos com três apicais póstero-dorsais e uma ântero-mediana. Quetotaxia: Ume2; Psu 1; Acr ausentes; Dc 2:3; IA 0:1; SA 3 última vestigial; Prs 1; PA 2; Eap 1; Esd 1; Epb ausente; Esb 1; Pep 2; Anp 6; Cat 1+1; merais delgadas em "L" invertido; parede pós-alar com sétulas; pontes supra-esquamais nuas.

Asas. Hialinas com intensa ofuscação ao longo de todas as veias e mácula escura iniciando na base das asas, estendendo-se ao longo da Costa até o ápice da $\mathrm{R}_{2+3}$, preenchendo completamente as células bc, c, sc e $\mathrm{r}_{1}$; veias negras; tégulas e basicostas castanho-avermelhadas; escleritos subcostais e veias tronco nus; junção da $\mathrm{R}_{2+3}$ com $\mathrm{R}_{4+5}$ nua ou com três sétulas muito reduzidas.

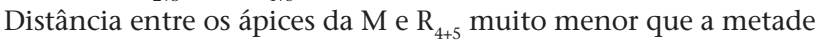
da distância entre os ápices da $\mathrm{R}_{2+3}$ e $\mathrm{R}_{4+5}$. Caliptras hialinas, ambas com bordas castanhas; margem interna das caliptras inferiores ortogonais ao escutelo.

Abdômen. Ventral e lateralmente amarelo desde a base até a margem posterior do $\mathrm{T}_{3}$ e dorsalmente até a região mediana do $\mathrm{T}_{3}$, o restante marrom enegrecido, com leve reflexão violácea; com fina pruinosidade branca distribuída por todo abdômen; $\mathrm{T}_{1+2}$ com linha de cerdas discais laterais pouco diferenciadas, paralelas à margem do tergito; $\mathrm{T}_{1+2}$ e $\mathrm{T}_{3}$ com um par de marginais laterais; $\mathrm{T}_{4}$ com 2-3 pares de marginais laterais; $\mathrm{T}_{5}$ com linha completa de marginais fracas, sem discais.

Terminália (Figs 9-15). $\mathrm{T}_{6}$ assimétrico, parcialmente fundido ao $\mathrm{T}_{7+8}$; extremidade apical do parafalo muito recurvada ventralmente e sem dentículos. 


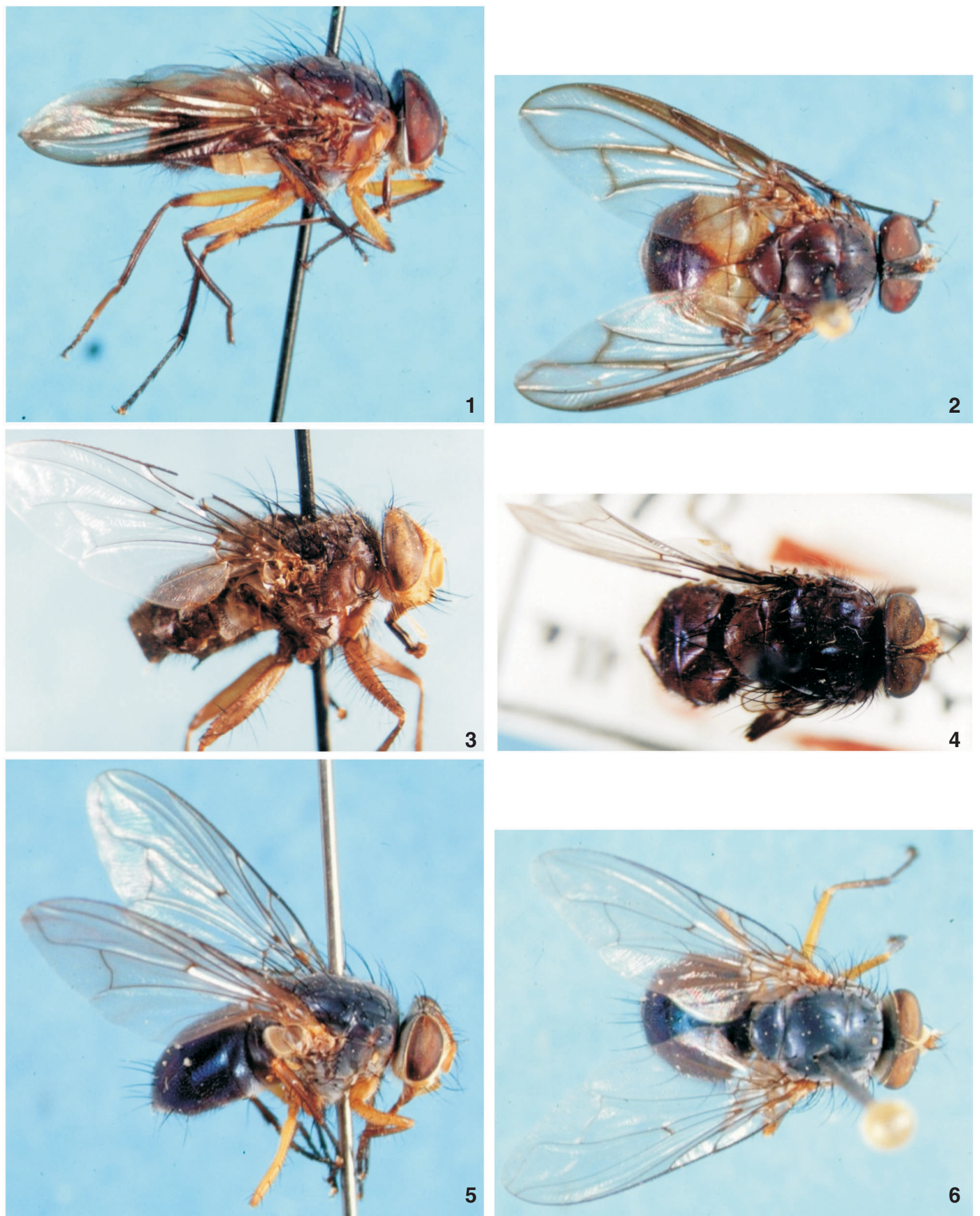

Figuras 1-6. Holótipos, vistas lateral e dorsal: (1-2) Giovanella bolivar sp. nov.; (3-4) Henriquella spicata sp. rev., comb. nov.; (5-6) Huascaromusca lara sp. nov. 


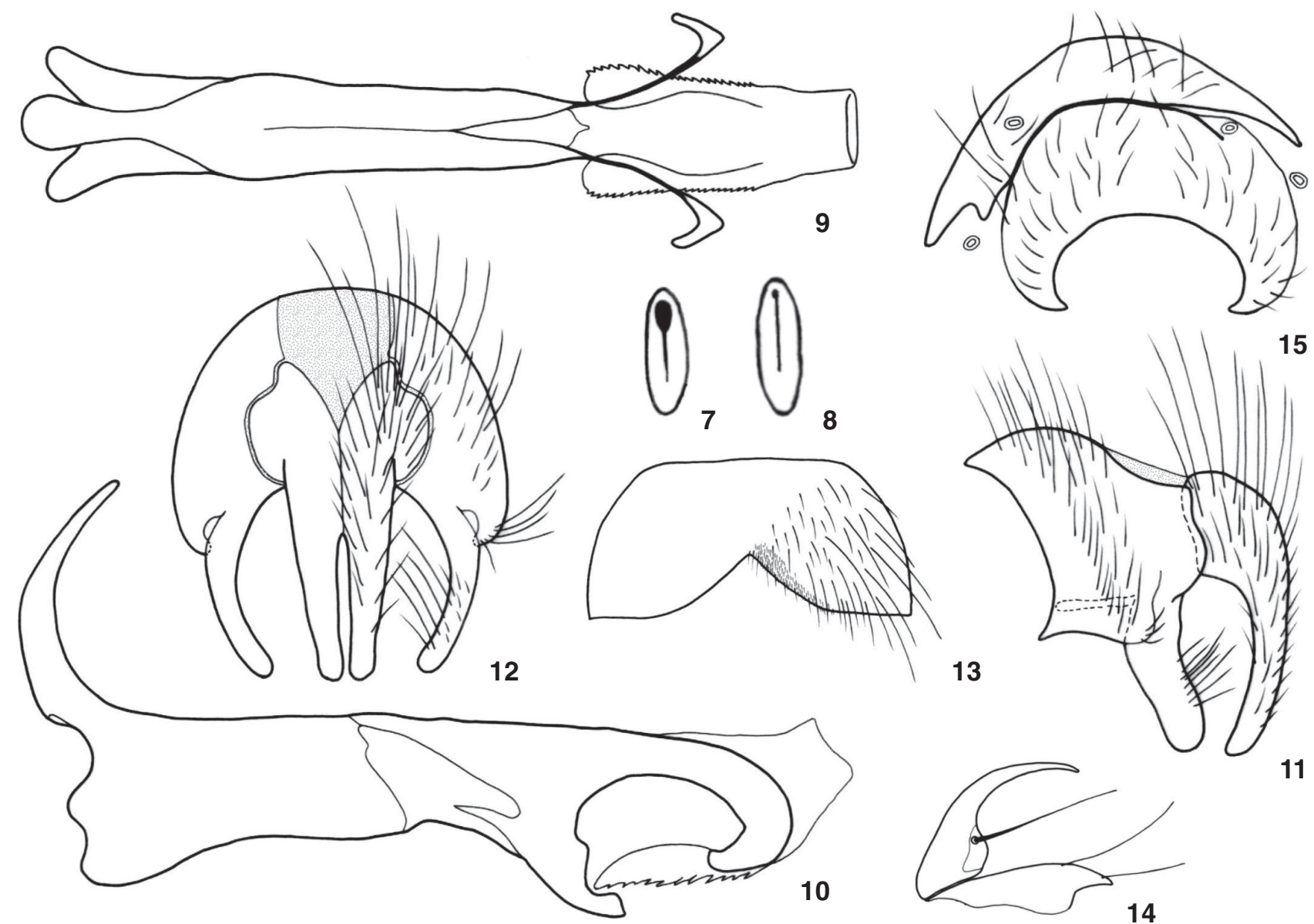

Figuras 7-15. (7) Espiráculo anterior de Huascaromusca vogelsangi Melo, 1967, para visualização do padrão encontrado na subfamília; (8-15) Giovanella bolivar sp. nov., holótipo: (8) espiráculo anterior; (9-15) terminália masculina: (9-10) edeago, vistas (9) dorsal e (10) lateral; (11-12) epândrio, surstilos e cercos, vistas (11) lateral e (12) posterior; (13) quinto esternito; (14) pós-gonito e pré-gonito, vista lateral; (15) tergitos 6 e $7+8$, vista dorsal.

Medidas. Comprimento do corpo $10 \mathrm{~mm}(\mathrm{n}=1)$.

Fêmea. Difere do macho no que segue.

Cabeça. Dicóptica; vita frontal larga, com pequena porção próxima à lúnula alaranjada e o restante negra; verticais externas ausentes; interfrontais vestigiais; frontais muito fracas a vestigiais; um par de orbitais proclinadas vestigiais; orbitais superiores divergentes muito fracas; verticais internas, ocelares e pós-ocelares como no macho; um par de paraverticais normais convergentes.

Tórax. SA 2; Esd ausentes.

Terminália. Epiprocto normal; $\mathrm{T}_{7}$ contínuo; $\mathrm{T}_{8}$ descontínuo situado lateralmente com projeções dorsais e sem cerdas; esternitos ovalados reduzidos; $\mathrm{St}_{8}$ evidenciado pela presença de cerdas; pleura sem cerdas; espermatecas filiformes.

Medidas. Comprimento do corpo $10 \mathrm{~mm}(\mathrm{n}=2)$.

Material-tipo examinado. Holótipo macho, etiquetado como segue: "VENEZUELA: Bolivar/ Kavanayen [537'60"N, 6147'60”W] 1000m./ Aug. 8, 1970/ R.E. Dietz IV, leg.”; “HOLOTYPE/ Giovanella bolivar/ S.R. Bonatto, 2002 [etiqueta retangular vermelha]" (USNM). Exemplar em excelente condição, terminália acondicionada em tubo plástico com glicerina, fixado ao alfinete. Parátipos: 1 fêmea com os mesmos dados do holótipo (USNM); 1 fêmea, Venezuela, Bolivar: Kavanayén (ptari-tepui 30 milhas N. Kavanayén, 1800 m), 17-19-VIII-1970, R.E. Dietz IV leg. (USNM). Etimologia. Nome alusivo à localidade-tipo. Distribuição. Venezuela (Bolivar: Kavanayén).

Considerações. Assemelha-se à $H$. semiflava (Aldrich, 1925) pelo padrão de coloração do abdômen, porém, pode ser facilmente distinguida pelo padrão de quetotaxia do tórax e abdômen, não possuindo cerdas discais no tergito 5, morfologia dos espiráculos anteriores, além do padrão de coloração das asas e estrutura da terminália do macho. 


\section{Henriquella Bonatto, gen. nov.}

Espécie-tipo: Mesembrinella spicata Aldrich, 1925.

Descrição. Mesonoto com pruinosidade dispersa, sem formar faixas; pós-oculares negras, em linha completa até a gena; com três cerdas umerais; cerdas acrosticais pré-suturais presentes; intra-alares 0:2; cerdas merais em " $\mathrm{L}$ " invertido; $\mathrm{T}_{5}$ sem discais; linha de cerdas discais laterais no $\mathrm{T}_{1+2}$ ausente.

Monofilia. Gênero com sua monofilia embasada na condição autapomórfica de Mesembrinella spicata: quinto esternito do macho com processos ao invés de lobos (Fig. 20); basifalo e epifalo dilatados (Fig. 16); cercos com extremidade superior com pente de cerdas e porção central membranosa (Figs 18 e 19).

Etimologia. Nome em homenagem ao Dr. José Henrique Guimarães, do Museu de Zoologia, Universidade de São Paulo, em reconhecimento ao seu trabalho com Diptera.

Considerações. Gênero monotípico, porém, entre os Mesembrinellinae, é um dos táxons com maior número de autapomorfias conhecidas.

\section{Henriquella spicata (Aldrich, 1925), sp. rev., comb. nov. Figs 3-4, 16-22}

Mesembrinella spicata Aldrich, 1925: 13 (Localidade-tipo: La Suiza, Costa Rica); Shannon, 1926: 121; Guimarães, 1977: 35 ( = Calliphora xanthorrhina Bigot, 1887) (error). Huascaromusca spicata; Hall, 1948: 79.

Diagnose. Espécimes de tamanho médio, coloração geral do corpo azul-escura a negra; vita frontal não obliterada; esternitos quadrangulares e imbricados com pouca exposição da membrana; tergitos sem cerdas marginais; quinto esternito do macho como na figura 20; edeago como na figura 16; extremidade apical do parafalo recurvada ventralmente com dentículos; cercos do macho como nas figuras 18 e 19 .

Condição autapomórfica. Propõe-se os seguintes estados de caracteres autapomórficos: quinto esternito do macho com processos, ao invés de lobos (Fig. 20); basifalo e epifalo dilatados (Fig. 16); cercos com extremidade superior com pente de cerdas e porção central dilatada e membranosa (Fig. 18).

Macho. Cabeça: holóptica; vita frontal não obliterada, inteiramente alaranjada, na porção mais estreita com aproximadamente duas vezes o diâmetro do ocelo anterior; fronte alargando-se gradativamente ao aproximar-se da lúnula; parafrontálias levemente enegrecidas próximo ao vértice, restante claro como as parafaciálias, ambas com pruinosidade prateada sem sétulas; genas amarelas com pruinosidade prateada, com pequenas sétulas negras; pós-genas e occipício com pruinosidade branca e pêlos flavos; face e membrana clipeal claras; triângulo ocelar castanho-enegrecido; pedicelos, escapos e flagelômeros alaranjados; palpos amarelos. Quetotaxia: dois pares de ocelares paralelas proclinadas, o par anterior levemente mais forte que o posterior; um par de pós-ocelares reclinadas divergentes; verticais externas ausentes; verticais internas cruzadas; um par de paraverticais convergentes; pós-oculares dis- tribuídas homogeneamente até a gena; interfrontais e orbitais proclinadas ausentes; terço basal da carena facial coberta por sétulas curtas negras; vibrissas cruzadas; subvibrissas com $2 / 3$ do comprimento das vibrissas.

Tórax. Mesonoto, pleura e úmero azul-escuros enegrecidos, com leve reflexão violácea de fundo, com fina pruinosidade branca dispersa por todo o tórax, sem formar faixas longitudinais no mesonoto; espiráculos anteriores e posteriores castanhos, estes com sétulas fracas ao redor da margem posterior; pernas com todos os artículos castanho-avermelhados escuros; fêmures medianos com três apicais póstero-dorsais e uma ântero-mediana. Quetotaxia. Ume 3; Psu 2; Acr 2:1; Dc 2:3; IA 0:2; SA 3; Prs 1; PA 3; Eap 1; Esd 1; Epb 1 fraca; Esb 1; Pep 2, contornadas por agrupamento de finas sétulas; Anp 8; Cat 1+1; merais em " $\mathrm{L}$ " invertido, paredes pós-alares com sétulas, pontes supra-esquamais nuas.

Asas. Inteiramente hialinas sem enfuscações; veias de coloração castanho-clara; tégulas castanho-enegrecidas; basicostas amarelas densamente setulosas; escleritos subcostais e veias tronco nus; junção da $\mathrm{R}_{2+3} \operatorname{com} \mathrm{R}_{4+5}$ possuindo duas sétu-

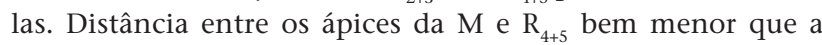
metade da distância entre os ápices da $\mathrm{R}_{2+3}$ e $\mathrm{R}_{4+5}$. Caliptras hialinas com bordas levemente acastanhadas; margem interna das caliptras inferiores ortogonais ao escutelo.

Abdômen. Coloração geral semelhante a do tórax, com base escura; tergitos com fina e densa pruinosidade branca mais concentrada nas laterais; $\mathrm{T}_{1+2}$ sem agrupamento de cerdas discais laterais. $\mathrm{T}_{3}$ sem marginais laterais; $\mathrm{T}_{4}$ e $\mathrm{T}_{5}$ sem linha de marginais; $\mathrm{T}_{5}$ sem discais.

Terminália. (Figs 16-22). $\mathrm{T}_{6}$ parcialmente fundido ao $\mathrm{T}_{7+8}$; extremidade apical do parafalo recurvada ventralmente e com dentículos; $\mathrm{St}_{6}$ com apódema bem desenvolvido; $\mathrm{St}_{5}$ com fortes processos enegrecidos ao invés dos lobos usuais; esternitos basais subquadrangulares, mais largos do que compridos e sem sétulas marginais na extremidade posterior; cercos com extremidade superior com pente de fortes cerdas e região mediana membranosa.

Medidas. Comprimento do corpo $9 \mathrm{~mm}(\mathrm{n}=1)$.

Fêmea. Não conhecida.

Material-tipo examinado. Holótipo macho, etiquetado como segue: “La Suiza $\left[9^{\circ} 50^{\prime} 60^{\prime}\right.$ N, 8337’0”W, 662 m; Província de Cartago]/ Costa Rica [etiqueta retangular manuscrita]"; "Pablo Schild/ Coll/ II-2-[19]23 [etiqueta retangular com data manuscrita]"; "?? [etiqueta retangular impressa em vermelho]"; "Type/ 26797/ No./ U.S.N.M. [etiqueta vermelha com algarismos manuscritos]"; "Mesembrinella/ spicata/ Ald. [etiqueta retangular com contorno preto, manuscrita por J.M. Aldrich]" (USNM). Exemplar em boas condições, sem a asa direita e com a esquerda com fratura próximo à base, sem a perna mediana esquerda, com terminália acondicionada em tubo plástico com glicerina, fixado ao alfinete.

Distribuição. Costa Rica (Cartago: La Suiza).

Considerações. Aldrich (1925) refere-se ao número de 


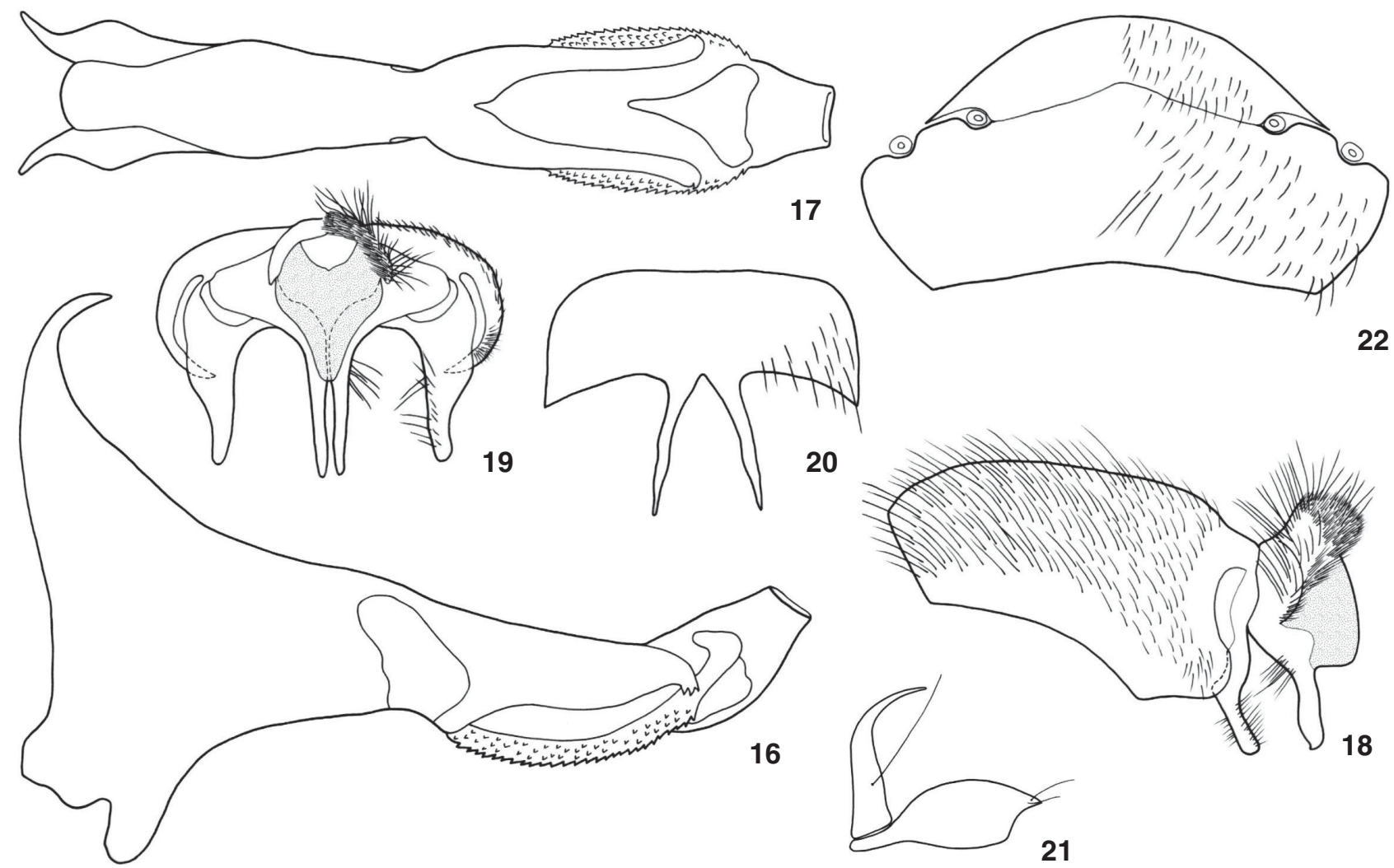

Figuras 16-22. Henriquella spicata sp. rev., comb. nov., holótipo, terminália masculina: (16-17) edeago, vistas (16) lateral e (17) dorsal; (18-19) epândrio, surstilos e cercos, vistas (18) lateral e (19) posterior; (20) quinto esternito; (21) pós-gonito e pré-gonito, vista lateral; (22) tergitos 6 e $7+8$, vista dorsal.

catálogo do USNM como 26796 para o holótipo, entretanto, o número encontrado no exemplar é 26797. GUIMARÃes (1977) considerou Mesembrinella spicata Aldrich, 1925 como sinônimo de Calliphora xanthorrhina Bigot, 1887, embora não tenha tido em mãos os exemplares-tipos. Após o exame do materialtipo dos dois táxons, constatou-se que são espécies distintas, desfazendo-se, portanto, a sinonímia e revalidando a espécie como Henriquella spicata comb. nov.

\section{Huascaromusca lara Bonatto, sp. nov. Figs 5-6, 23-29}

Diagnose. Espécie de tamanho médio a pequeno, coloração geral do corpo negra, com reflexões azul-esverdeadas no tórax e abdômen; com densa e fina pruinosidade branca no tórax sem formar faixas no mesonoto; duas umerais; Acr 0:2; Dc 2:2; cercos do macho como nas figuras 25 e 26; fêmea com $\mathrm{T}_{6}, \mathrm{~T}_{7}$ e $\mathrm{T}_{8}$ descontínuos.

Condição autapomórfica. A forma do quinto esternito do macho (Fig. 27) possui conformação distinta daquele das demais espécies de Mesembrinellidae.
Holótipo macho. Cabeça: holóptica; vita frontal obliterada, pequena porção próxima ao triângulo ocelar negra e porção basal alaranjada; fronte alargando-se abruptamente ao aproximar-se da lúnula, na porção mais estreita com três vezes o diâmetro do ocelo anterior; parafrontálias negras e parafaciálias amarelas ambas com pruinosidade prateada, sem sétulas; palpos e genas amarelos estas com pruinosidade prateada, com curtas sétulas negras; pósgenas com pêlos alaranjados; face e membrana claras; triângulo ocelar negro; pedicelos, escapos e flagelômeros alaranjados; occipício com pruinosidade branca com esparsos pêlos flavos. Quetotaxia: dois pares de ocelares paralelas, tão longas quanto as verticais internas, sendo o primeiro par mais forte; um par de pós-ocelares paralelas bem desenvolvidas; verticais externas ausentes; verticais internas cruzadas; um par de paraverticais paralelas bem desenvolvidas; pós-oculares alternando-se uma longa e duas curtas, distribuídas homogeneamente até a gena; interfrontais e orbitais proclinadas ausentes; base da carena facial com três sétulas curtas e negras; vibrissas cruzadas; subvibrissas com $2 / 3$ do comprimento das vibrissas.

Tórax. Mesonoto, úmeros e pleuras negros, com reflexos azul-esverdeados, cobertos por fina e densa pruinosidade bran- 


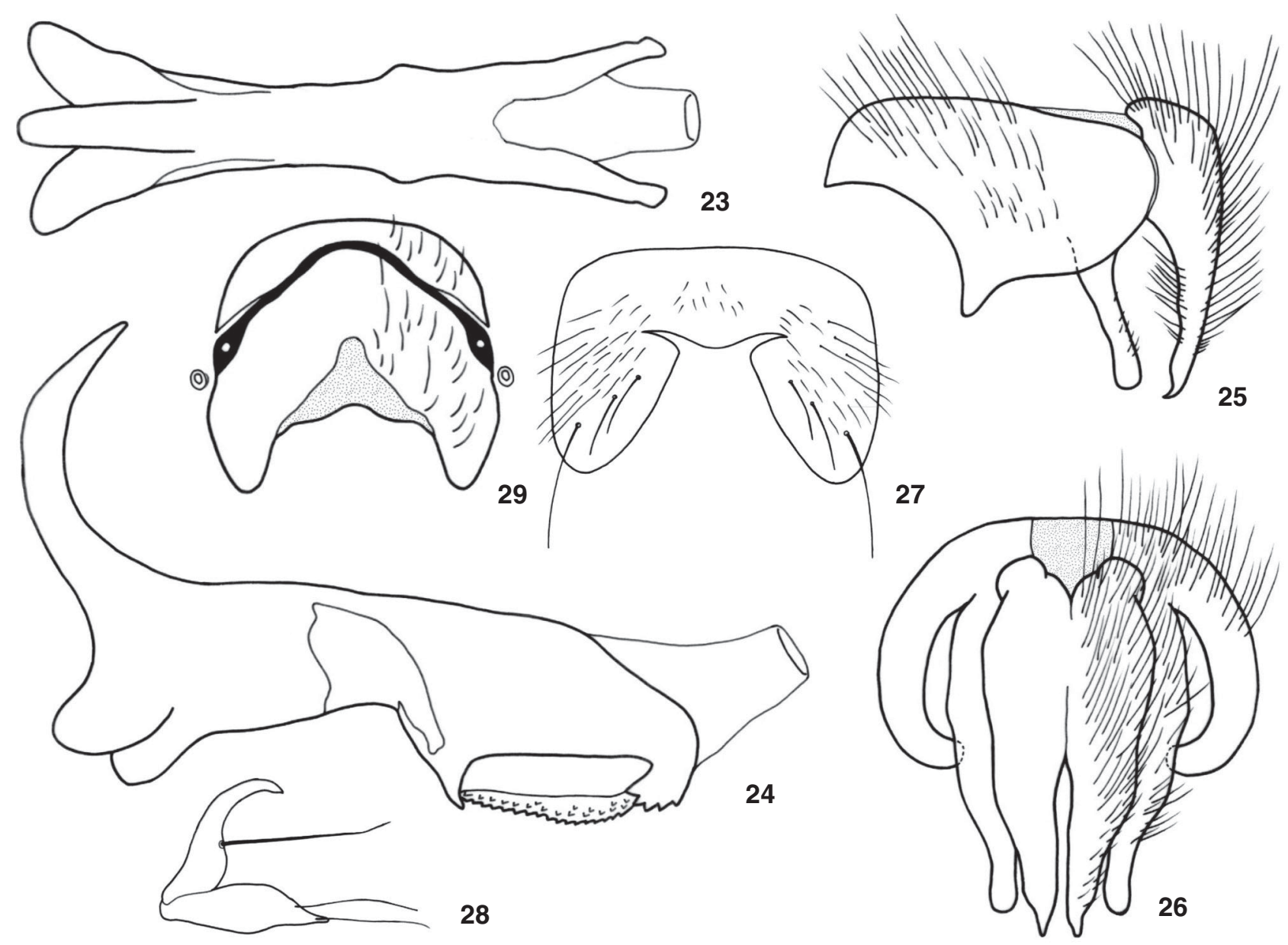

Figuras 23-29. Huascaromusca lara sp. nov., holótipo, terminália masculina: (23-24) edeago, vistas (23) dorsal e (24) lateral; (25-26) epândrio, surstilos e cercos, vistas (25) lateral e (26) posterior; (27) quinto esternito; (28) pós-gonito e pré-gonito, vista lateral; (29) tergitos 6 e $7+8$, vista dorsal.

ca distribuída homogeneamente por todo o tórax, não formando faixas longitudinais; espiráculos anteriores e posteriores flavos, estes com sétulas claras concentradas na sua porção dorsal posterior; coxas e fêmures amarelos; tíbias e tarsos castanho-avermelhados-claros, os dos primeiros pares de pernas com tonalidade levemente mais clara; fêmures medianos com duas apicais póstero-dorsais e uma ântero-mediana. Quetotaxia: Ume 2; PU 2; Acr ausentes; Dc 2:2; IA 0:2; SA 3; Prs 1; PA 3 última fraca; Eap 1; Esd 1; Esa ausente, Epb 1 vestigial; Esb 1; Pep 3; Anp 7; Cat 1+2; merais fortes em "L" invertido; parede pós-alar fracamente ciliado; ponte supra-esquamal nua.

Asas. Hialinas, sem máculas, com leve ofuscação ao redor da r-m; veias de coloração clara; tégulas e basicostas amarelas; escleritos subcostais e veia tronco nus; junção de $\mathrm{R}_{2+3}$ com $\mathrm{R}_{4+5}$ possuindo duas sétulas; distância entre os ápices da $\mathrm{M}$ e $\mathrm{R}_{4+5}$ menor que a metade da distância entre os ápices da $\mathrm{R}_{2+3} \mathrm{e}$ $\mathrm{R}_{4+5}$. Caliptras hialinas, as inferiores levemente opacas, as su- periores com borda castanha; margem interna das caliptras inferiores ortogonais ao escutelo.

Abdômen. Coloração semelhante a do tórax, porém, com leve reflexos violáceos, com intensa pruinosidade fina e branca, distribuída homogeneamente por todos os tergitos e esternitos; $\mathrm{T}_{1+2}$ com linha de cerdas discais laterais paralelas à margem do tergito; $\mathrm{T}_{1+2}$ e $\mathrm{T}_{3}$ com um par de marginais laterais; $\mathrm{T}_{4}$ e $\mathrm{T}_{5}$ com linha completa de marginais fortes; $\mathrm{T}_{5}$ com linha completa de fortes discais; esternitos alongados.

Terminália (Figs 23-29). $\mathrm{T}_{6}$ parcialmente fundido ao $\mathrm{T}_{7+8}$; extremidade apical do parafalo recurvada ventralmente e com dentículos.

Medidas. Comprimento do corpo $8 \mathrm{~mm}(\mathrm{n}=1)$.

Fêmea. Difere do macho no que segue.

Cabeça. Dicóptica; vita frontal larga, alaranjada na base, castanho-alaranjada até as interfrontais e negra no vértice; verticais externas fracas pouco diferenciadas das pós-oculares; ver- 
ticais internas convergentes; dois pares de ocelares divergentes, o primeiro par com o dobro do comprimento do segundo; dois pares de paraverticais convergentes; um par de orbitais proclinadas fracas; um par de orbitais superiores divergentes; parafrontália negra com uma linha de pequenas sétulas proclinadas ao lado e ao longo das frontais.

Tórax. Sétulas dos espiráculos posteriores menos desenvolvidas do que no macho; tíbias com coloração castanhoavermelhada mais escura do que no macho.

Terminália. Epiprocto normal; $\mathrm{T}_{6}$ e $\mathrm{T}_{7}$ descontínuos; $\mathrm{T}_{8}$ descontínuo situado lateralmente e sem cerdas; esternitos basais alongados, os demais ovais reduzidos; $\mathrm{St}_{8}$ evidenciado pela presença de cerdas; pleura sem cerdas; espermatecas filiformes.

Medidas. Comprimento do corpo $9 \mathrm{~mm}(\mathrm{n}=5)$.

Material-tipo examinado. Holótipo macho, etiquetado como segue: "VENEZUELA: Lara/ Parque Nac[ional]./ Yacambu [7 $7^{\circ} 16^{\prime} \mathrm{N}, 68^{\circ} 24^{\prime} \mathrm{W}$, altitude $57 \mathrm{~m}$ ]/ 6-8-IV-81"; “A.S. Menke/ L. Hollenberg/ Collectors; HOLOTYPE/ Huascaromusca/ lara/ S.R. Bonatto [etiqueta vermelha com contorno preto]" (USNM). Exemplar em excelente condição; terminália acondicionada em tubo plástico com glicerina, fixado ao alfinete. Parátipos: 5 fêmeas com os mesmos dados do holótipo (3 USNM e 2 DZUP).

Distribuição. Venezuela (Lara: [Barquisimeto], Parque Nacional de Yacambú).

Etimologia. Nome específico alusivo à localidade-tipo.

Considerações. Huascaromusca lara sp. nov. assemelhase muito à $H$. decrepita (Séguy, 1925) da qual se diferencia pela ausência das acrosticais e pela distribuição das dorsocentrais (2:2), além da morfologia da terminália do macho.

\section{AGRADECIMENTOS}

Agradecemos aos curadores e/ou intermediários no empréstimo de material: Dr. Claudio J.B. de Carvalho (DZUP); Dr. Norman E. Woodley e Dr. Wayne N. Mathis (USNM). Aos Doutores Claudio J.B. de Carvalho e Renato C. Marinoni (DZUP), pelas discussões e elucidações taxonômicas e nomenclaturais. Ao Dr. Albino M. Sakakibara (DZUP) pela confecção de fotografias do material-tipo examinado e pelas correções e sugestões taxonômicas. Ao Conselho Nacional de Desenvolvimento Científico e Tecnológico (CNPq) pela concessão de bolsa de estudos para o desenvolvimento deste estudo.

\section{REFERÊNCIAS BIBLIOGRÁFICAS}

Aldrich, J.M. 1925. New Diptera or two-winged flies in the United States National Museum. Proceedings of the United States Natural Museum, Washington, 66 (18): 1-36.

Carvalho, C.J.B. DE \& M.S. Couri. 1992. Descrição de Agenamyia exotica, sp. n. (Diptera, Muscidae), chave para as espécies do gênero e considerações sobre sua posição sistemática. Revista Brasileira de Entomologia, São Paulo, 36 (1): 21-24.

GuimarãES, J.H. 1977. A systematic revision of the Mesembrinellidae, stat. nov. (Diptera, Cyclorrhapha). Arquivos de Zoologia, São Paulo, 29 (1): 1-109.

HaLl, D.G. 1948. The blowflies of North America. Washington, Thomas Say Foundation, The Entomological Society of America, vol. 4, 477p.

Hennig, W. 1973. 31. Diptera (Zweiflügler). Handbuch der Zoologie, Berlin, 4 (2) 2/31: 1-337.

Marinoni, L. \& L.V. Knutson. 1992. Revisão do gênero Neotropical Protodictya Malloch, 1933 (Diptera, Sciomyzidae). Revista Brasileira de Entomologia, São Paulo, 36 (1): 25-45.

McAlpine, J.F. 1981. Morphology and terminology: adults, p. 963. In: J.F. McAlpine; B.V. Peterson; G.E. Shewell; H.J.Teskey; J.R. Vockeroth \& D.M. Wood (Eds). Manual of Nearctic Diptera. Ottawa, Research Branch, Agriculture Canada, Monograph 27, vol. 1, VI+674p.

O'HARA, J.E. 1982. Classification, phylogeny and zoogeography of the North American species of Siphona Meigen (Diptera: Tachinidae). Quaestiones Entomologicae, Alberta, 18: 261380.

Shannon, R.C. 1926. Synopis of the American Calliphoridae (Diptera). Proceedings of the Entomological Society of Washington 28 (6): 115-139.

Rognes, K. 1991. Blowflies (Diptera, Calliphoridae) of Fennoscandia and Denmark. Fauna Entomologica Scandinavica, Leiden, 24: 1-272.

McAlpine, J.F. 1989. Phylogeny and classification of Muscomorpha, p. 1397-1518. In: J.F. McAlpine \& D.M. Wood (Eds). Manual of Nearctic Diptera. Ottawa, Research Branch Agriculture Canada, Monograph 32, vol. 3, VI+1333-1581p.

Peris, S.V. \& J.C. Mariluis. 1984. Notas sobre Mesembrinellidae. EOS - Revista Española de Entomología, Madrid, 60: 251265.

Recebido em 22.XII.2004; aceito em 08.IX.2005. 